\title{
MITOGEN ACTIVATED PROTEIN KINASE: FUNCTION AND RESPONSES TO DIFFERENT STRESSES IN PLANTS
}

\author{
Sara Khan ${ }^{1}$, Nadia Iqbal ${ }^{1}$, Farah Deeba ${ }^{1}$, Raheela Jabeen ${ }^{1 *}$ \\ ${ }^{1}$ Department of Biochemistry and Biotechnology, The Women University, Multan, Pakistan

\section{*Corresponding Author} \\ Dr. Raheela Jabeen \\ Department of Biochemistry and Biotechnology, The Women University, Multan, Pakistan \\ drraheela.9054@wum.edu.pk
}

\begin{abstract}
Mitogen Activated Protein Kinase (MAPK) pathway is the most commonly studied signaling mechanisms, consisting of different groups of protein kinases that participate in regularly connecting interpretation of external stimuli that can change in gene expression or cellular organization within eukaryotic systems. The MAP kinase pathways functions in plants cell signaling (intra- and extra). MAPK cascades follow a response system. MAP kinases are the component of kinase constituents that deliver signals from sensors to responders in eukaryotes including plants. Several pathways are activated under different environmental stresses. Stimulating agents may be biological (biotic) like microbial infections or environmental (abiotic) like temperatures threshold, high salt concentration, drought, heavy metal, Ultraviolet radiation, ozone gases and reactive oxygen species (ROS). The involvement of MAPK signaling pathway in different stresses has been widely studied. In this review we also try to highlight MAPK cascades, its regulation, functions and recent findings in various cellular processes against stress conditions.
\end{abstract}

Key words: MAPK, External and internal stimulus, S/T Serine/threonine T (E/D), Y Threonine (glutamate/ aspartate) tyrosine, Sensory system and Stress Response. 


\section{INTRODUCTION}

Mitogen-activated protein kinases (MAPKs) are one of the main members of enzymes transferases that transfer the functional group or catalyzing phosphorylation on serine or threonine residues of specific proteins substrates $(1)$.

Protein kinases and phosphatases take part in signaling pathways through the phosphorylation and dephosphorylation of proteins. These alterations in proteins lead to the initiation of immune systems. These changes also act as stimulant for developing phenomena like growth, division and cellular differentiation. The basic of MAP kinase pathway is regulation of gene expression in association with understanding of external stimulant, depending upon phosphorylation of kinases (2). Among the most common mechanisms, are by which functions of cells are regulated and are evolutionarily conserved in the most of eukaryotes, especially plants.

MAP kinase pathways are evolutionary preserved and fundamental signal transduction pathways. MAP kinase cascades also critically perform a function in plant maturation augmentation, and to living and environmental strain responses. An extensive studied of the mitogen activated protein with kinases $M K K$ gene family is still needed in cotton (3).

\section{Localization of Map Kinases}

Plant MAPKs are mostly present in the organelles as in cytosol or nucleus and may also be transferred from cytoplasm to the genetic material in some conditions. MAPKs actively take part in the signal transmit to the nucleus, thus allowing targeted expression of specific genes at elevated level in response to environmental changes detected at surface of the cell. Plant MAP Kinases substrates essentially present a better understanding of the core signaling mechanisms. In this review summary, we try to focus on different aspects of MAPK that includes the nuclear signaling of plant MAPKs, the changes in activity of plant MAPKs, their initiation as well as their nuclear re-localization components like nuclear substrates of plant MAPKs in reference to different stresses (biotic stress, abiotic stress and development) (4). Latest findings in plants specify that these pathways explained above are vital to basic physical functions that involved defense mechanisms, immunity, hormonal responses, regulation of cell cycle and abiotic stress signaling (5). MAPK pathway from now is a topic of great importance because it links multiple molecules that receives and sense information to nuclear and cellular reactions in eukaryotic plants. 


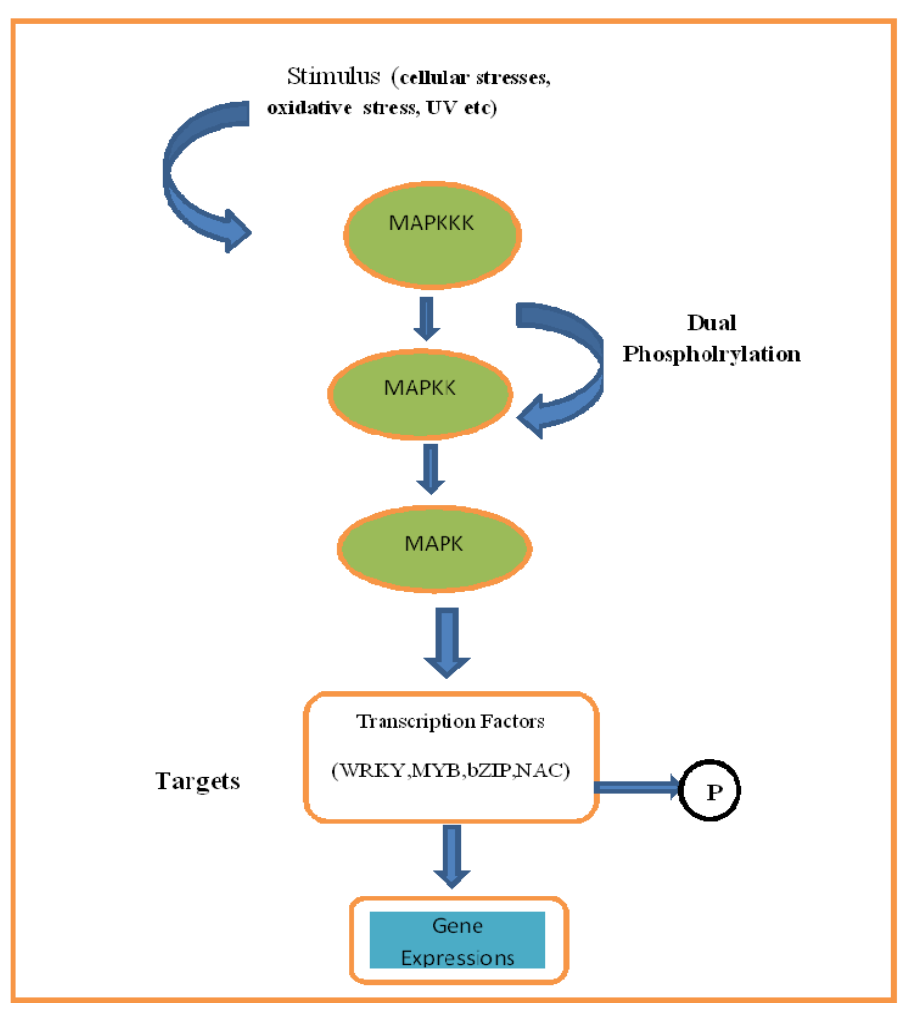

Figure 1: A signal transduction pathway directs the signal from MAPKKKK to MAPK by triggering a series of phosphorylation events, being transported to the nucleus where it is involved in the phosphorylation of other proteins(TF).

\section{MAPK Cascades Regulation in Plants}

Eukaryotic protein (MAP) kinase cascades are involved in down regulation of molecules or proteins that respond to stimuli including environmental stresses (biotic or abiotic) according to their adaptation to cell internal responses. The core association of a MPK pathway consists of a 3-kinase constituent. The transduction of input signals by MAPK cascades consists of three types of kinase including mitogen activated protein (MAP) kinase kinase kinases (MAPKKKs; also represented as MAP3Ks or MEKKs), MAP kinase kinases (MKKs; called as MAP2Ks or MEKs) and MAP kinases (MAPKs; also known as MPK) (6). The phosphorylation of mitogen protein with single kinase (MPK) is the last step in pathway that initiated by phosphorylation of amino acids residues like threonine and tyrosine. Multiple sub members for each of these 3 phosphorylation steps of mitogen proteins may also be conveyed in a cell. This process explains the conversion of signals due to interacting properties of kinases in each step (7). MAP with 3 kinases consists of amino acids serine/ threonine residues that phosphorylate downstream other kinase groups like MAP2K at a preserved S/T-X3-5-S/T amino acid sequences and it further phosphorylates MAPK on conserved amino acids tyrosine and threonine T-X-Y sequences. 
Deactivation or dis-phosphorylation occurred due to specific amino acid phosphatases (8). The structural characteristics or integrity of MAP kinases pathways can also be intervenes by different supporting, adaptor proteins and their domains. The schematic output of MAPK cascade can be shown in figure 1.

\section{Evolution and Kinase Properties}

Different projects that figure out order of genome, present the sequences of mostly studied MAP kinase constituents of many different plant species $(9,10)$ Arabidopsis thaliana studied as model plant and contain nearly 110 genes encoding MAP kinases pathways. The genome sequence of Arabidopsis species like in Arabidopsis thaliana permitted the identification of mitogen related protein with different kinase group MAP3Ks, MAP2Ks, and MAPKs with number 80, 10 and 20 respectively (11). Kinase analogs of this particular kind have been recognized in other species too (12). With an increasing development of gene sequences, categorization of these kinases according to their motifs significance into respective families is an important and challenging task. Highly preserved or homology in MAP kinase pattern can be traced from different species of plants that include A. thaliana, Oryza sativa, Vitis vinifera and Sorghum bicolor. Concord MAPK significant motif alignments could be evoked on base of Clustal alignment tool or databases GenBank (13).Analysis of model plant genome surprisingly showed a large number of genes encoding components of MAPK pathway, thus highlighting their important role in signal transduction (14). Recent researches have established key roles of noted MAP kinase flow process in growing process, cell proliferation and study in various environmental strain stimuli like temperature changes, salt concentration variability, cutting, ultraviolet rays and heavy oxides (15).

\section{Structural Characteristics of Map Kinases Types}

\section{MAP3Ks}

MAP3Ks (MAPKKKs or MEKKs) recognized as a basic large initiator of kinases andon basis of sequence analysis, divided into three main classes. As a model study Arabidopsis MAPKKKs is divided into MEKK-like (21 members), Raf-like (48 members) and ZIK-like (11 members; also known as WNK with no lysine (K) MAPKKKs (14) MEKK-like kinases fall into four subcategories (A1 - A4); In A1 subgroup A. thaliana includes four functionally characterized protein kinases: MAP/ERK kinase kinase 1 (AtMEKK1, also called 
AtMAPKKK8), AtMEKK2 (AtMAPKKK9), AtMEKK3 (AtMAPKKK10), and AtMEKK4

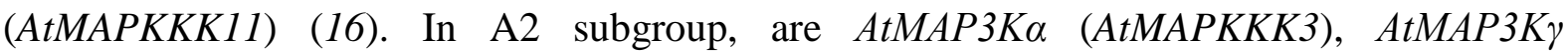
(AtMAPKKK5), AtYODA (AtMAPKKK4), while subgroup A3 comprises AtANP1 (also called AtMAPKKK1), AtANP2 (AtMAPKKK2), AtANP3 (AtMAPKKK12) and last functional proteins

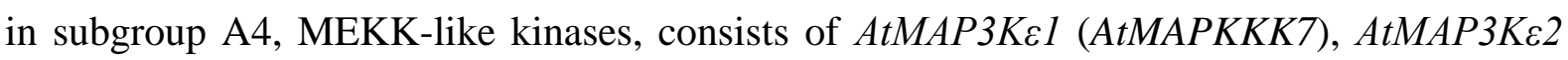
(AtMAPKKK6) and AtMAPKKK13-21 in A. thaliana, (17).

\section{MAP2Ks}

MAP2Ks recognized as MEKs also MKKs, they have been arranged into 4 sets named A-D and are explained for rice as well as Arabidopsis (18). Set A consists of ArabidopsisMKK1, $M K K 2$ so as to operate upstream of the MAPK MPK4. MKK1 also MKK2 mediate innate immunity responses and $M K K 2$ is too involved in reactions to salt moreover cold stress (19). MKKs set B contain ArabidopsisMKK3 that has subsequent homologs inrice. In set A called NTF domain discriminated Kinases in this cluster (20). The nuclear force bring in of content proteins are improved by nuclear transfer factor domains (21). It points out that MAP2Ks of plant among NTF domains engaged in cytoplasmic-nuclear bargaining. Besides this, $M K K 3$ as well take parts in flows so as to obtain through pathogens moreover are reliant on signaling of jasmonic acid(22). It is concerning to analyze the MKK3 co-localization, assumed downstream MAPKs as well as consider the systems of opening of JA reactive MAPK elements on the sub cellular stage. Set C contains $M K K 4, M K K 5$ also set D contains residual MKKs 7-10 as of Arabidopsis. Commonly the entire phyla of plant shows to utilize further restricted numeral of $M K K s$ contrast to additional MAPK elements. Through genomic studies close relations of plant MAP2Ks with other plants species indicates the similarity in functions. For example some members are suggested to activate the other members downstream (23), whereas some act upstream apparently in an unnecessary way (24).

\section{MAPKs}

The MAPKs class is the last kinase of MAPK cascade component. MAPKs feature the conserved T-X-Y motif, which is phosphorylated during signal transduction as in extracellular signal-regulated kinase $(E R K)$ by MAPKKs. Based on sequence similarities, Arabidopsis consists of the 20 MAPKs that have been divided into two subtypes, TEY (12 MAPKs) and TDY (8 MAPKs). The MAPKs of the TEY subtype carrying amino acids T-E-Y (Thr-Glu-Tyr) motif and can be divided into three groups $(\mathrm{A}-\mathrm{C})$. The group $\mathrm{D}$ is more evolutionarily distant 
and formed by MAPKs of the TDY subtype, which contain a T-D-Y (Thr-Asp-Tyr) motif at the phosphorylation site (25). Group A includes Arabidopsis (thaliana) MPK3 and MPK6, and their orthodox that have been evidenced in Oryza sativa and wood species. The MAPKs studied above get initiation in response to stresses/ strains like biotic and abiotic (26). Thus group A shows no homology with land plants. Group A TEY MAPKs include AtMPK3, AtMPK6 and AtMPK10 in Arabidopsis (27). MAPKs in Bgroup is in relation with MPK4 (A.thaliana) are involved in abiotic stain responses (28). Group B includes AtMPK4, AtMPK5, AtMPK11-13, whereas AtMPK1, AtMPK2, AtMPK7, AtMPK14are members of group C (29). Group D has a characteristic feature that is a Carboxyl-end generally docking site that may act as a cut off target for MAP with two kinases.

In the kinase classes of different species with diverse functions, MAK has a pattern of CDC2/CDK2 class/family that is regulators of cell cycle (30). Plant MAKs may function in reduction cell division and development of male production cells (31). Conversely, functional analysis shows that MAPK constituents are essential to explain that MAK kinases are isolated division of the MAP kinase family. Different analysis of commented MAPKs many plants species are thought to involve in adaptations to new environment. Eight to ten sub-members of MAPKs in different species are noted. This notation showed variant expressions in each that suggests rapid evolution of functions among plant MAPKs and their subsets (20).

\section{Abiotic Stresses and Regulation}

Abiotic stresses have been known to constitute a crucial problem in the field of cultivation. The division and understanding of the signal cascades mediated by strain tolerance, is a necessary step to cultivate more strong plants (32). In several plant classes, a number of MAP kinases set off responses to various abiotic strains and slowly emerge the goals of these kinases.

The amino acids Cys and His (C2H2)-type zinc-finger protein (ZFP) family, mostly present in Arabidopsis thaliana, almost about 176 members, is largest putative TF in plants. Of the ZFP members, 143 considered to be Arabidopsis specific and only about 33 members are in other eukaryotes. Zinc finger protein is one of the important transcription factor and have role in regulation of gene expression. One of its type, ZAT6, is substrate to MAP6 kinase and undergo phosphorylation to execute its role during seed sprouting under salt concentration and osmotic stress (33). Overexposure of mutation at phosphorylated site compromised the improved osmotic and salt concentration strain tolerance in an experiment with the wild type zinc finger domain gene (ZAT6) (34). 


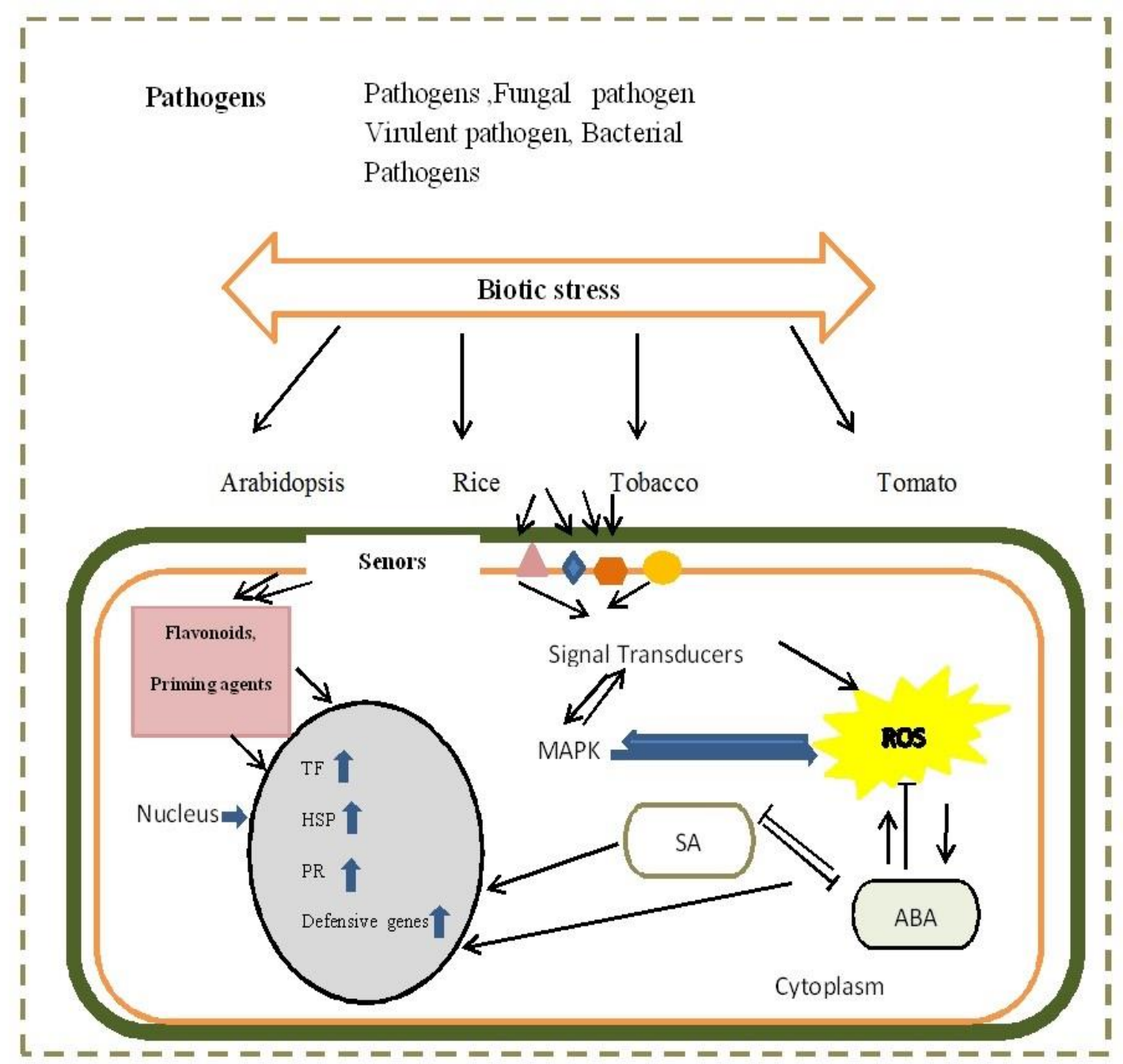

Figure 2: Biotic strain has to be first sensed by the plant cell, and then the information is converted to downstream-located pathway(s). Reactive oxygen species and $\mathrm{Ca}++$ are known among others to play a prominent role as (messengers) and (MAP) kinases cascades have been shown to be used by both types of stresses. Hormones,priming agent secondary metabolites upregulate proteins like (TF), pathogenesis related (PR) and defense genes.

Plants growth, metabolism and its productivity mainly depends upon the temperature. Change in temperature is an essential factor among abiotic stresses. Plant tissues consist of large amount of water and for cell survival, temperature is the key factor. Temperature changes is the main cause of environmental stresses. Plants can grow healthy in wide ranges of temperatures depending on species and developmental stages throughout their life (35). Beyond these ranges, plants could suffer from extreme temperature change. So far, no specific receptor has been identified in plants in response to extreme temperature stresses. However, the plasma membrane itself could act as primary sensor of temperature fluctuations (36). In 
fact, extremely high or low temperature results in structural modifications in plasma membrane that can trigger downstream-specific signaling events. Extremely low extreme temperatures increase the stiffness of the plasma membrane, on the other hand high temperatures increase membrane permeability. Both these changes are perceived as primary stimuli signals that trigger fluxes of second messengers (e.g., $\mathrm{Ca}+{ }^{2}$ ) to activate specific heat response. Heat responses include the increased expression of heat shock proteins (HSPs) heat shock transcription factors (HSFs); cold shock domain containing proteins (CSDPs) (37); ROS scavengers; antioxidants; compatible solutes; calcium-dependent protein kinases (CDPKs) and MAP kinases. Some of MAPK, including Arabidopsis calcium dependent MAPK6 is activated by heat and regulate the activity of vacuolar processing enzyme (VPE) (38). In a recent transcriptional profiling study carried out on cassava, a tropical drought-tolerant crop, homologous of the Arabidopsis MPK4, was identified as one of the genes upregulated at low temperature $\left(7^{0} \mathrm{C}\right)(39)$.

In cotton, the relative mRNA transcript of the MAP kinase, GhMAPK, increased significantly in plant seedlings subjected to cold temperature $\left(4^{0} \mathrm{C}\right)(40)$, suggesting that MAP kinases may have defensive roles against cold effect on root cells. The MAPK cascade composed of MEKK1, MKK2 and MPK4/MPK6 functions in salt stress signaling in Arabidopsis, is also functional in cold stress pathway (15). The mkk2 mutant presents a freezing sensitive phenotype with no observable activity neither for MPK4 nor MPK6, suggesting that MKK2 is an upstream activator of MPK4 and MPK6 in cold signaling. This finding is consistent with previous studies showing that cold stress activates MEKK1, MPK3, MPK4 and MPK6 (12).

\section{Cross-Talk between Different Kinases in Abiotic Stress Signaling}

The word cross-talk is usually refer to conditions in which characteristics signaling cascades share many intermediates/ components affects one another. Several abiotic strains give both specific and precise consequences on plant production. On the basis of idea a unique non-living strain tolerance pathways it is commonly observe that plant life have more than one strains and sign transmission paths, which may also interact at diverse stages in the pathway. The strong evidence has been observed on basis of involvement of MAP kinases in abiotic strain signaling. The Arabidopsis genome contains about eighty MAP with three kinases, ten MAP with two kinases and twenty MAPKs which offer a range of cross-speak between different stains. Almost six components of MAP kinase pathways get initiated by different type of stresses (oxidative stress, drought, wound, cold). Different constituents of MAP kinase cascade for 
instance AtMPK6 is involved in various signaling pathways, and also in critical developmental techniques inclusive of plant parts like epidermal patterning and development of embryo and anther The practical interplay of MP with kinase 6 has been revealed by a complete group of MAP2Ks which includes kinase 2, and different modules (15) MKK3 (41), mitogen kinase kinase 4 and $5 M K K 4 / M K K 5$ (42) and $M K K 9$ (43). Thus, it shows that MAP kinase pathways act as points of junction in strain signaling or it act as main component in gene regulation in oppose to one-of-a-kind stresses. Table illustrates list of MAPKs from different plant sources involved in abiotic stresses.

\section{Biotic Stress and Regulation}

The causes of biotic stresses in plants are viruses, insects, microbes, yeasts and others. Biotic strain resources openly attack their host and deprive of its food thus lead to slow movement of plants and in severe circumstances ultimately death of the host plant. In field of cultivation, the main reason behind the loss of crops before and after harvest is biotic stress. Plants also lack an acquired defense system as compared to vertebrates_so are more vulnerable to different diseases or stresses. Hence lack the ability of memorizing latent previous viruses. Plant life also has developed an abundance of refined procedures to act against biotic strains instead of lacking an acquired immune mechanism The genetic basis of these protection mechanisms is safe in memory of the plants hereditary. A large number of biotic strain resistance genes get encode by plant genome, among them are important cultivation crops. In the previous twosome of years, it was decisively determined that MAP kinase plays a principal role in immune system against pathogens in species like Arabidopsis and other plants.

Components primarily involved in between biological and environmental causes of strains. The plant cell firstly sensed both these stresses and then the signals transferred downstream-located pathway(s).Stressors might involve sensory messengers and transducers in different type of stresses. Among the known messengers ROS and $\mathrm{Ca}++$ are important and in $\mathrm{Ca}++$ and ROS interaction mechanism, signal output MAPKs are centrally controlled. Due to its importance, ROS might be represented as fundamental component in the integration of mutual stresses during stress conditions. The entire importance to stress adaptation involves plant hormones signals regulation. For instance while ABA is generally involved in non-living (abiotic) strain, other hormones salicylic acid and ethylene JA/ET response towards biotic strain. ABA signaling takes part positively towards pre-influx defense. Different plant hormones work in interacting manner and their activation depend upon each other signals. For instance ABA and 
JA/ET signaling are positively responsive to each other. The activation of salicylic acid signal because of microbial encounter may reduce $\mathrm{ABA}$ reactions (44). The communication of these hormones signaling results in increased protection from microbes. In contrast to this some hormones signaling like abscisic acid have undesirable effects on complete acquired resistance, thus increasing infection exposure at the site of infection. Releasing molecules, secondary metabolites, preparing agents, additionally some biochemical placed within the cytoplasm results in activation of protein (transcription factors TF), protection genes and stress protein (HSP). Some additional genes involved in defense against strain thus cause the physiological and genotypic expressions (45).The schematic mechanism of MAPK activation in response against plant pathogens shown in (figure 2).

Plants reply to biotic strains (pathogens attack) through activation of multistep protection responses, hardening of outer covering, stimulation of the hypersensitive response (HR), the localized cellular dying at the point of infection and instant response of reactive oxygen species (ROS) (46). However, there's presence of cross-signaling among the several hormonal cascades, and the particular nature of this signaling in the course of immediate biotic and abiotic stresses further need to be studied.

\section{MAPK Cascades in Plant Hormonal Signaling}

One of the plant hormones abscisic acid ABA act as a basic element in regulating many developmental and functional processes including seed inactivation and sprouting (47), seedling growth (48) and also adaptation to various biotic and abiotic stress conditions (49). ABA signal pathway has been thoroughly considered and consists of numerous constituents including MAP kinases. Recently, the main constituents of the ABA signal pathways have been considered and suggested relatively (50). These investigations have definitely explained the protein network that identify and transfer ABA signals. Several past revisions show the contribution of MAPK cascades in ABA-facilitated responses that involve defense responses (antioxidant) and germ sprouting (51). Thus, the interactions between MAPK pathways, abscisic acid signaling and other pathways have been started to be explained.

The application of exogenous ABA to plant structures cause its initiation against stress conditions thus result in protein storage, of MAPKs activation and transcriptional regulation suggesting a dominating part in its pathways in abscisic acid signaling (52). ABA works through an intricate network of signal transduction cascades involve the subsequent binding of 
the hormone to different receptors of cell which set off responses together with the regulation of expression of stress-responsive genes (53).

Recently in latest years, researchers have significantly focus on gene expression in several plant species that facilitated through abscisic acid. ABA signal change over pathways control expression of gene, including changes in complete transcription process and its strength. (54).

Table 1: List of MAPKs from different plant sources involved in abiotic stresses.

\begin{tabular}{|c|c|c|c|c|}
\hline $\begin{array}{l}\text { Components of } \\
\text { MAPK cascade }\end{array}$ & $\begin{array}{l}\text { Plant } \\
\text { (d ifferent species) }\end{array}$ & S ignal responses & Title & References \\
\hline MAPKK, MKK2 & Arabidopsis & $\begin{array}{l}\text { Hypo-osmolarity } \\
\text { Ozone } \\
\text { Cold and salt stress }\end{array}$ & $\begin{array}{l}\text { "Involvement of MPK4 } \\
\text { in osmotic stress } \\
\text { response pathways in } \\
\text { cell suspensions and } \\
\text { plantlets of A. } \\
\text { thaliana" } \\
\text { "The MKK2 pathway } \\
\text { mediates cold and salt } \\
\text { stress signaling in } \\
\text { Arabidopsis" }\end{array}$ & $(63,64)$ \\
\hline $\begin{array}{l}\text { OSMAPK5 } \\
\text { MAPKK1 }\end{array}$ & Rice (Oryza sativa) & $\begin{array}{l}\text { Wound, drought, salt, } \\
\text { cold } \\
\text { Salt, drought }\end{array}$ & $\begin{array}{l}\text { "Disease resistance } \\
\text { and abiotic stress } \\
\text { tolerance in rice are } \\
\text { inversely modulated by } \\
\text { an abscisic acid- } \\
\text { inducible mitogen- } \\
\text { activated protein } \\
\text { kinase" }\end{array}$ & (66) \\
\hline NtMPK4 & $\begin{array}{l}\text { Tobacco(Nicotiana } \\
\text { tabacum) }\end{array}$ & $\begin{array}{l}\text { Salt and osmotic stress, } \\
\text { Ozone. } \\
\text { Wound, ozone } \\
\text { tolerance }\end{array}$ & $\begin{array}{l}\text { "Osmotic stress } \\
\text { induces rapid } \\
\text { activation of a salicylic } \\
\text { acid-induced protein } \\
\text { kinase and a homolog } \\
\text { of protein kinase } \\
\text { ASK1 in tobacco } \\
\text { cells." }\end{array}$ & (68) \\
\hline GhMPK7 & Cotton(Gossypium) & $\begin{array}{l}\text { Wounding, cold, } \\
\text { salinity. } \\
\text { Salt, wounding }\end{array}$ & $\begin{array}{l}\text { "GhMPK7, a novel } \\
\text { multiple stress- } \\
\text { responsive cotton } \\
\text { group C MAPK gene, } \\
\text { has a role in broad } \\
\text { spectrum disease } \\
\text { resistance and plant } \\
\text { development. }\end{array}$ & (70) \\
\hline $\begin{array}{l}\text { ZmMPK7 } \\
\text { ZmMAPK5 } \\
\text { ZmMPK5 } \\
\text { ZmSIMK1 }\end{array}$ & Maize(Zea mays) & $\begin{array}{l}\mathrm{H} 2 \mathrm{O} 2, \text { Osmotic stress } \\
\mathrm{H} 2 \mathrm{O} 2, \mathrm{PEG}, \mathrm{NaCl} \text {, } \\
\mathrm{CdC1} \text {, cold, wound, } \\
\mathrm{UV} \text {. } \\
\text { Low temperature stress } \\
\text { Salt stress }\end{array}$ & $\begin{array}{l}\text { "Overexpression of } \\
\text { maize mitogen- } \\
\text { activated protein } \\
\text { kinase gene, } \\
\text { ZmSIMK1 in } \\
\text { Arabidopsis increases } \\
\text { tolerance to salt stress" }\end{array}$ & (72) \\
\hline
\end{tabular}

In abscisic acid gene regulation, functioning reaction includes proteins that are (transcription factors TFs), which identify and bind to similar molecule in the upstream area to their goal genetic material $(55,56)$.

In Arabidopsis thaliana, ABA got regulated by almost $10 \%$ protein coding genes (49). Several genes of MAPK family of all three kinases get transcribed, including modules of kinases in Arabidopsis like AtMAPK1, AtMAPK2 (57), AtMPK3, AtMPK5, AtMPK7, AtMPK18, AtMPK20 (58), AtMKK9, AtMAPKKK1 (ANP1), AtMAPKKK5, AtMAPKKK15, 
AtMAPKKK16, AtMAPKKK17,AtMAPKKK18,AtMAPKKK19 (58), AtMAPKKK20 (59), and AtRaf6, AtRaf12, and AtRaf35, all of which are regulated at the transcriptional level, exhibiting possible participation of these kinases in ABA signaling., Despite the large number of ABA-regulated genes, the functions of most of genes in ABA signaling have not yet been characterized.

ABA signaling also studied in cotton Gossypium hirsutum. The expression of GhMPK17 is upregulated by hormone ABA and salt. Over expression of GhMPK17in A. thaliana showed increased salt and osmotic stress tolerance, as well as changes in levels of $\mathrm{H}_{2} \mathrm{O}_{2}$ and expression of other stress-related genes (60). Recently in new work a novel cotton MAPKKK gene, GhMAPKKK49 was isolated and treated exogenously with $\mathrm{ABA}$ or $\mathrm{H}_{2} \mathrm{O}_{2}$. As GhMAPKKK49 also interacts with GhMKK4 and GhMKK9, it is assumed that a GhMAPKKK49-GhMKK4 or GhMAPKKK49- MKK9 cascade has role in ABA- and $\mathrm{H}_{2} \mathrm{O}_{2}$-mediated responses to abiotic stress.

In plant defense mechanisms, MAPK has clearly involved in different studies. Different MAPK motifs in A.thaliana are involved in hormones signaling including Jasmonic acid (JA) and salicylic acid (SA) pathways. For example AtMPK4 positively regulates JA responses, whereas AtMEKK1-AtMKK1/2-AtMPK4 cascade appears to function as a negative regulator of SA signaling and plant innate immunity (61). On the other hand, activation of the AtMKK3AtMPK6 cascade in A.thalianaby JA represses a negative regulator of JA biosynthesis genes, leading to suppression of JA production (62). Many studies showed the examples of hormone signaling in MAP kinase cascades demonstrate the importance of this collaboration for plants in response to wounding. However, there is still very little knowledge related to this cooperation and further studies are needed for better understanding to develop improved resistance of plants to pathogens.

\section{Conclusion}

In this study, an extensive overview of the working of MAPKs and their complex interaction in plants has been summarized. MAP kinase modules critically function in the conversion of signals flow through phosphorylation of signaling targets in downward direction of pathways. This signaling includes other kinases, cytoskeletal proteins, transcription regulators and enzymes in all membrane-bounded organisms cell. Generally MAP kinase pathway comprises minimum of 3 successively acting serine/threonine kinases, including MAP kinase with three (MAPKKK), two (MAPKK) and finally the single kinase (MAPK) and each activates the next 
kinase in the cascade upon phosphorylation, Latest advancement in our study have directed towards the finding of new regulatory systems. In this thorough review the finding has shown the developing role of crosstalk between the protein modules of several signaling pathways that regulate biotic and abiotic stress at cellular level. Here we provided a summary of MAPK cascades in different stress conditions and about different plants species in which MAPK cascades are responsible for protein phosphorylation and signal transduction events associated with plant hormone signaling and therefore they play an essential role in the regulation of development and stress signaling. Some of MAP Kinases have been identified which are involved in ABA, JA, SA signaling. Various studies of MAPK demonstrate their complex structure, extensive crosstalk and dynamics of the signaling network.

Signaling mechanism for MAPK inactivation involved some hormone signaling but still need to be study. The search of the findings like regulation of MAPK in gene activation or translation, cross talk and interactions between MAPK cascades and MAPK distributed through which route within cell will provide stimulant in establishing role of MAPK in plants. MAP kinases pathways, like other cascades display advancement in role of regulatory properties and MAPK research relating to all basic yields.

\section{REFERENCES}

1. Xu, C.; Liu, R.; Zhang, Q.; Chen, X.; Qian, Y.; Fang, W., The diversification of evolutionarily conserved MAPK cascades correlates with the evolution of fungal species and development of lifestyles. Genome biology and evolution. 2017, 9 (2), 311-322.

2. Sturgill, T. W.; Ray, L. B., Muscle proteins related to microtubule associated protein-2 are substrates for an insulin-stimulatable kinase. Biochemical and biophysical research communications. 1986,134 (2), 565-571.

3. Taj, G.; Agarwal, P.; Grant, M.; Kumar, A., MAPK machinery in plants: recognition and response to different stresses through multiple signal transduction pathways. Plant signaling \& behavior. 2010,5 (11), 1370-1378.

4. Bigeard, J.; Hirt, H., Nuclear signaling of plant MAPKs. Frontiers in plant science. 2018,9, 469.

5. Tena, G.; Boudsocq, M.; Sheen, J., Protein kinase signaling networks in plant innate immunity. Current opinion in plant biology. 2011,14 (5), 519-529. 
6. Raja, V.; Majeed, U.; Kang, H.; Andrabi, K. I.; John, R., Abiotic stress: interplay between ROS, hormones and MAPKs. Environmental and Experimental Botany. 2017,137, 142157.

7. Madhani, H. D.; Fink, G. R., The riddle of MAP kinase signaling specificity. Trends in Genetics. 1998,14 (4), 151-155.

8. Luan, S., Protein phosphatases in plants. Annual Review of Plant Biology. 2003,54 (1), 6392.

9. Group, M., Mitogen-activated protein kinase cascades in plants: a new nomenclature. Trends in plant science .2002,7 (7), 301.

10. Hardie, D., Plant protein serine/threonine kinases: classification and functions. Annual review of plant biology. 1999,50 (1), 97-131.

11. Colcombet, J.; Hirt, H., Arabidopsis MAPKs: a complex signalling network involved in multiple biological processes. Biochemical Journal. 2008,413 (2), 217-226.

12. Crooks, G. E.; Hon, G.; Chandonia, J.-M.; Brenner, S. E., WebLogo: a sequence logo generator. Genome research. 2004,14 (6), 1188-1190.

13. Chenna, R.; Sugawara, H.; Koike, T.; Lopez, R.; Gibson, T. J.; Higgins, D. G.; Thompson, J. D., Multiple sequence alignment with the Clustal series of programs. Nucleic acids research. 2003,31 (13), 3497-3500.

14. Hardie, D., Plant protein serine/threonine kinases: classification and functions. Annual review of plant biology. 1999,50 (1), 97-131.

15. Teige, M.; Scheikl, E.; Eulgem, T.; Dóczi, R.; Ichimura, K.; Shinozaki, K.; Dangl, J. L.; Hirt, H., The MKK2 pathway mediates cold and salt stress signaling in Arabidopsis. Molecular cell. 2004,15 (1), 141-152.

16. Danquah, A.; de Zelicourt, A.; Colcombet, J.; Hirt, H., The role of ABA and MAPK signaling pathways in plant abiotic stress responses. Biotechnology advances . 2014, 32 (1), 40-52.

17. Chaiwongsar, S.; Strohm, A.; Su, S.-H.; Krysan, P. J., Genetic analysis of the Arabidopsis protein kinases MAP3Ke1 and MAP3Ke2 indicates roles in cell expansion and embryo development. Frontiers in plant science. 2012,3, 228.

18. Chardin, C.; Schenk, S. T.; Hirt, H.; Colcombet, J.; Krapp, A., Mitogen-Activated protein kinases in nutritional signaling in Arabidopsis. Plant Science. 2017,260, 101-108. 
19. Mészáros, T., Helfer, A., Hatzimasoura, E., Magyar, Z., Serazetdinova, L., Rios, G., ... \& Bögre, L. The Arabidopsis MAP kinase kinase MKK1 participates in defence responses to the bacterial elicitor flagellin. The Plant Journal, 2006. 48(4), 485-498.

20. Hamel, L. P., Nicole, M. C., Sritubtim, S., Morency, M. J., Ellis, M., Ehlting, J., ... \& Martin, G. Ancient signals: comparative genomics of plant MAPK and MAPKK gene families. Trends in plant science, 2006. 11(4), 192-198.

21. Steggerda, S. M., \& Paschal, B. M. Regulation of nuclear import and export by the GTPase Ran. International review of cytology, 2002. 217, 41-91.

22. Dóczi, R., Brader, G., Pettkó-Szandtner, A., Rajh, I., Djamei, A., Pitzschke, A., ... \& Hirt, H. (2007). The Arabidopsis mitogen-activated protein kinase kinase MKK3 is upstream of group $\mathrm{C}$ mitogen-activated protein kinases and participates in pathogen signaling. The Plant Cell, 2007. 19(10), 3266-3279.

23. Qiu, J. L., Fiil, B. K., Petersen, K., Nielsen, H. B., Botanga, C. J., Thorgrimsen, S., ... \& Brodersen, P. Arabidopsis MAP kinase 4 regulates gene expression through transcription factor release in the nucleus. The EMBO journal, 2008. 27(16), 2214-2221.

24. Asai, T.; Tena, G.; Plotnikova, J.; Willmann, M. R.; Chiu, W.-L.; Gomez-Gomez, L.; Boller, T.; Ausubel, F. M.; Sheen, J., MAP kinase signalling cascade in Arabidopsis innate immunity. Nature. 2002,415 (6875), 977-983.

25. Bigeard, J.; Hirt, H., Nuclear signaling of plant MAPKs. Frontiers in plant science .2018,9, 469.

26. Seo, S.; Katou, S.; Seto, H.; Gomi, K.; Ohashi, Y., The mitogen-activated protein kinases WIPK and SIPK regulate the levels of jasmonic and salicylic acids in wounded tobacco plants. The Plant Journal. 2007,49 (5), 899-909.

27. Mohanta, T. K.; Arora, P. K.; Mohanta, N.; Parida, P.; Bae, H., Identification of new members of the MAPK gene family in plants shows diverse conserved domains and novel activation loop variants. BMC genomics. 2015,16 (1), 58.

28. Qiu, J. L., Fiil, B. K., Petersen, K., Nielsen, H. B., Botanga, C. J., Thorgrimsen, S., ... \& Brodersen, P. Arabidopsis MAP kinase 4 regulates gene expression through transcription factor release in the nucleus. The EMBO journal, 2008. 27(16), 2214-2221.

29. Wankhede, D. P.; Misra, M.; Singh, P.; Sinha, A. K., Rice mitogen activated protein kinase kinase and mitogen activated protein kinase interaction network revealed by in-silico docking and yeast two-hybrid approaches. PLoS One. 2013,8 (5). 
30. Miyata, Y.; Akashi, M.; Nishida, E., Molecular cloning and characterization of a novel member of the MAP kinase superfamily. Genes to Cells. 1999,4 (5), 299-309.

31. Shinkai, Y.; Satoh, H.; Takeda, N.; Fukuda, M.; Chiba, E.; Kato, T.; Kuramochi, T.; Araki, Y., A testicular germ cell-associated serine-threonine kinase, MAK, is dispensable for sperm formation. Molecular and cellular biology. 2002,22 (10), 3276-328

32. Gull, A.; Lone, A. A.; Wani, N. U. I., Biotic and Abiotic Stresses in Plants. In Abiotic and Biotic Stress in Plants, IntechOpen: 2019.

33. Xie, M.; Sun, J.; Gong, D.; Kong, Y., The Roles of Arabidopsis C1-2i Subclass of C2H2type Zinc-Finger Transcription Factors. Genes. 2019,10 (9), 653.

34. Liu, Q.-L.; Zhong, M.; Li, S.; Pan, Y.-Z.; Jiang, B.-B.; Jia, Y.; Zhang, H.-Q., Overexpression of a chrysanthemum transcription factor gene, DgWRKY3, in tobacco enhances tolerance to salt stress. Plant physiology and biochemistry. 2013,69, 27-33.

35. Went, F., The effect of temperature on plant growth. Annual Review of Plant Physiology. $1953,4(1), 347-362$

36. Sangwan, V.; Örvar, B. L.; Beyerly, J.; Hirt, H.; Dhindsa, R. S., Opposite changes in membrane fluidity mimic cold and heat stress activation of distinct plant MAP kinase pathways. The Plant Journal. 2002,31 (5), 629-638.

37. Karlson, D.; Imai, R., Conservation of the cold shock domain protein family in plants. Plant Physiology. 2003,131 (1), 12-15.

38. Li, Z.; Yue, H.; Xing, D., MAP Kinase 6-mediated activation of vacuolar processing enzyme modulates heat shock-induced programmed cell death in Arabidopsis. New Phytologist. 2012,195 (1), 85-96.

39. An, D.; Yang, J.; Zhang, P., Transcriptome profiling of low temperature-treated cassava apical shoots showed dynamic responses of tropical plant to cold stress. BMC genomics. $2012,13(1), 64$.

40. Wang, M.; Zhang, Y.; Wang, J.; Wu, X.; Guo, X., A novel MAP kinase gene in cotton (Gossypium hirsutum L.), GhMAPK, is involved in response to diverse environmental stresses. BMB Reports. 2007,40 (3), 325-332.

41. Takahashi, F.; Yoshida, R.; Ichimura, K.; Mizoguchi, T.; Seo, S.; Yonezawa, M.; Maruyama, K.; Yamaguchi-Shinozaki, K.; Shinozaki, K., The mitogen-activated protein kinase cascade MKK3-MPK6 is an important part of the jasmonate signal transduction pathway in Arabidopsis. The Plant Cell. 2007,19 (3), 805-818. 
42. Ortiz-Masia, D.; Perez-Amador, M. A.; Carbonell, J.; \& Marcote, M. J.,Diverse stress signals activate the C1 subgroup MAP kinases of Arabidopsis. FEBS letters, 2007. 581(9), 1834-1840.

43. Yoo, S.-D.; Cho, Y.-H.; Tena, G.; Xiong, Y.; Sheen, J., Dual control of nuclear EIN3 by bifurcate MAPK cascades in C 2 H 4 signalling. Nature. 2008,451 (7180), 789-795.

44. agodzik, P.; Tajdel-Zielinska, M.; Ciesla, A.; Marczak, M.; Ludwikow, A., Mitogenactivated protein kinase cascades in plant hormone signaling. Frontiers in plant science 2018,9, 1387.

45. Rejeb, I. B.; Pastor, V.; Mauch-Mani, B., Plant responses to simultaneous biotic and abiotic stress: molecular mechanisms. Plants. 2014,3 (4), 458-475.

46. Zhang, S.; Klessig, D. F., Resistance gene N-mediated de novo synthesis and activation of a tobacco mitogen-activated protein kinase by tobacco mosaic virus infection. Proceedings of the National Academy of Sciences. 1998,95 (13), 7433-7438.

47. Mine, A.; Berens, M. L.; Nobori, T.; Anver, S.; Fukumoto, K.; Winkelmüller, T. M.; Takeda, A.; Becker, D.; Tsuda, K., Pathogen exploitation of an abscisic acid-and jasmonate-inducible MAPK phosphatase and its interception by Arabidopsis immunity. Proceedings of the National Academy of Sciences. 2017,114 (28), 7456-7461.

48. Trupkin, S. A.; Auge, G. A.; Zhu, J.-K.; Sánchez, R. A.; Botto, J. F., SALT OVERLY SENSITIVE 2 (SOS2) and interacting partners SOS3 and ABSCISIC ACIDINSENSITIVE 2 (ABI2) promote red-light-dependent germination and seedling deetiolation in Arabidopsis. International Journal of Plant Sciences .2017,178 (6), 485493.

49. Wang, P.; Zhao, Y.; Li, Z.; Hsu, C.-C.; Liu, X.; Fu, L.; Hou, Y.-J.; Du, Y.; Xie, S.; Zhang, C., Reciprocal regulation of the TOR kinase and ABA receptor balances plant growth and stress response. Molecular cell. 2018,69 (1), 100-112. e6.

50. Fujii, H., Chinnusamy, V., Rodrigues, A., Rubio, S., Antoni, R., Park, S. Y., ... \& Zhu, J. K. In vitro reconstitution of an abscisic acid signalling pathway. Nature, 2009. 462(7273), 660.

51. de Zelicourt, A.; Colcombet, J.; Hirt, H., The role of MAPK modules and ABA during abiotic stress signaling. Trends in plant science. 2016,21 (8), 677-685.

52. Li, Y.; Qin, L.; Zhao, J.; Muhammad, T.; Cao, H.; Li, H.; Zhang, Y.; Liang, Y., SIMAPK3 enhances tolerance to tomato yellow leaf curl virus (TYLCV) by regulating 
salicylic acid and jasmonic acid signaling in tomato (Solanum lycopersicum). PLoS One. 2017,12(2).

53. Eisenach, C.; Baetz, U.; Huck, N. V.; Zhang, J.; De Angeli, A.; Beckers, G. J.; Martinoia, E., ABA-induced stomatal closure involves ALMT4, a phosphorylation-dependent vacuolar anion channel of Arabidopsis. The Plant Cell. 2017,29 (10), 2552-2569.

54. Cutler, S. R.; Rodriguez, P. L.; Finkelstein, R. R.; Abrams, S. R., Abscisic acid: emergence of a core signaling network. Annual review of plant biology. 2010,61, 651-679.

55. Zhang, H.; Liu, Y.; Wen, F.; Yao, D.; Wang, L.; Guo, J.; Ni, L.; Zhang, A.; Tan, M.; Jiang, M., A novel rice C2H2-type zinc finger protein, ZFP36, is a key player involved in abscisic acid-induced antioxidant defence and oxidative stress tolerance in rice. Journal of experimental botany. 2014,65 (20), 5795-5809.

56. Fujita, Y.; Fujita, M.; Shinozaki, K.; Yamaguchi-Shinozaki, K., ABA-mediated transcriptional regulation in response to osmotic stress in plants. Journal of plant research. 2011,124 (4), 509-525.

57. Umezawa, T.; Sugiyama, N.; Anderson, J. C.; Takahashi, F.; Ishihama, Y.; Peck, S. C.; Shinozaki, K., Protein Phosphorylation Network in Abscisic Acid Signaling. In Plant and Microbe Adaptations to Cold in a Changing World, Springer: 2013; pp 155-164.

58. Wang, R.-S.; Pandey, S.; Li, S.; Gookin, T. E.; Zhao, Z.; Albert, R.; Assmann, S. M., Common and unique elements of the ABA-regulated transcriptome of Arabidopsis guard cells. BMC genomics. 2011,12 (1), 216.

59. Li, K.; Yang, F.; Zhang, G.; Song, S.; Li, Y.; Ren, D.; Miao, Y.; Song, C.-P., AIK1, a mitogen-activated protein kinase, modulates abscisic acid responses through the MKK5MPK6 kinase cascade. Plant physiology. 2017,173 (2), 1391-1408.

60. Zhang, H.; Liu, Y.; Wen, F.; Yao, D.; Wang, L.; Guo, J.; Ni, L.; Zhang, A.; Tan, M.; Jiang, M., A novel rice C2H2-type zinc finger protein, ZFP36, is a key player involved in abscisic acid-induced antioxidant defence and oxidative stress tolerance in rice. Journal of experimental botany. 2014,65 (20), 5795-5809.

61. Pitzschke, A.; Hirt, H., Mitogen-activated protein kinases and reactive oxygen species signaling in plants. Plant physiology. 2006,141 (2), 351-356.

62. Takahashi, F.; Yoshida, R.; Ichimura, K.; Mizoguchi, T.; Seo, S.; Yonezawa, M.; Maruyama, K.; Yamaguchi-Shinozaki, K.; Shinozaki, K., The mitogen-activated protein kinase cascade MKK3-MPK6 is an important part of the jasmonate signal transduction pathway in Arabidopsis. The Plant Cell. 2007,19 (3), 805-818. 
63. Droillard, M.-J.; Boudsocq, M.; Barbier-Brygoo, H.; Laurière, C., Different protein kinase families are activated by osmotic stresses in Arabidopsis thaliana cell suspensions: involvement of the MAP kinases AtMPK3 and AtMPK6. FEBS letters. 2002,527 (1-3), 43.

64. Ahlfors, R.; Macioszek, V.; Rudd, J.; Brosché, M.; Schlichting, R.; Scheel, D.; Kangasjärvi, J., Stress hormone-independent activation and nuclear translocation of mitogen-activated protein kinases in Arabidopsis thaliana during ozone exposure. The Plant Journal. 2004,40 (4), 512-522.

65. Xiong, L.; Yang, Y., Disease resistance and abiotic stress tolerance in rice are inversely modulated by an abscisic acid-inducible mitogen-activated protein kinase. The Plant Cell. $2003,15(3), 745$.

66. Kumar, K.; Rao, K. P.; Sharma, P.; Sinha, A. K., Differential regulation of rice mitogen activated protein kinase kinase (MKK) by abiotic stress. Plant physiology and biochemistry. 2008,46 (10), 891-89.

67. Mikołajczyk, M.; Awotunde, O. S.; Muszyńska, G.; Klessig, D. F.; Dobrowolska, G., Osmotic stress induces rapid activation of a salicylic acid-induced protein kinase and a homolog of protein kinase ASK1 in tobacco cells. The Plant Cell. 2000,12 (1), 165-178.

68. Gomi, K.; Ogawa, D.; Katou, S.; Kamada, H.; Nakajima, N.; Saji, H.; Soyano, T.; Sasabe, M.; Machida, Y.; Mitsuhara, I., A mitogen-activated protein kinase NtMPK4 activated by SIPKK is required for jasmonic acid signaling and involved in ozone tolerance via stomatal movement in tobacco. Plant and Cell Physiology. 2005,46 (12), 1902-1914.

69. Wang, M.; Zhang, Y.; Wang, J.; Wu, X.; Guo, X., A novel MAP kinase gene in cotton (Gossypium hirsutum L.), GhMAPK, is involved in response to diverse environmental stresses. BMB Reports. 2007,40 (3), 325-332.

70. Shi, J.; An, H.-L.; Zhang, L.; Gao, Z.; Guo, X.-Q., GhMPK7, a novel multiple stressresponsive cotton group C MAPK gene, has a role in broad spectrum disease resistance and plant development. Plant molecular biology. 2010,74 (1-2), 1-17.

71. Berberich, T.; Sano, H.; Kusano, T., Involvement of a MAP kinase, ZmMPK5, in senescence and recovery from low-temperature stress in maize. Molecular and General Genetics MGG. 1999,262 (3), 534-542.

72. Gu, L.; Liu, Y.; Zong, X.; Liu, L.; Li, D.-P.; Li, D.-Q., Overexpression of maize mitogenactivated protein kinase gene, ZmSIMK1 in Arabidopsis increases tolerance to salt stress. Molecular biology reports. 2010,37 (8), 4067-4073. 